\section{Reciprocal Grafts of Standard and Dwarf Peach Alter Dry-matter Partitioning and Root Physiology}

\author{
D.M. Glenn ${ }^{1}$ and R. Scorza ${ }^{2}$ \\ U.S. Department of Agriculture-Agricultural Research Service, \\ Appalachian Fruit Research Station, Kearneysville, WV 25430
}

Additional index words. indole acetic acid, auxin, cytokinin, gibberellic acid, root conductivity, Prunus persica

\begin{abstract}
In reciprocal grafts of tall ('Elberta' and 'Loring') and dwarf ('Empress' and 'Juseito') peach (Prunus persica Batsch.) phenotypes, we measured dry-matter partitioning, resistance to root system water flow, and phytohormone content of xylem exudate. Scion characteristics determined the phenotype and growth characteristics of the tree irrespective of the rootstock. Tall phenotypes had higher dry weight and lower root resistance to water flow than dwarf phenotypes. Cytokinin-like activity and auxin levels in xylem sap were higher in dwarf than in tall phenotypes; whereas gibberellinlike activity was unaffected by either rootstock or scion. The scion of peach influenced phytohormone levels and resistance to water flow in the root system in addition to root and shoot growth.
\end{abstract}

No peach rootstock is available that reduces scion size as much as that found in apple (Malus domestica Borkh.). However, there are some rootstocks being tested that reduce size as much as 30\% (Rom, 1988). The mechanisms of dwarfing in tree fruit are unclear but appear to involve the activity of endogeneous plant hormones. Studies reviewed by Faust (1989) have shown that endogeneous levels of gibberellin (GA), abscisic acid (ABA), and auxin-like compounds ([indole-3-acetic acid IAA)] may or may not be correlated with variation in growth habits in fruit trees. Dwarf peach seedlings used as rootstocks do not impart a dwarfing char-

Received for publication 26 Apr. 1991. Accepted for publication 17 Oct. 1991. We gratefully acknowledge the assistance of Jerry Cohen (Plant Hormone Laboratory, USDA-ARS, Beltsville, Md.) in the determination of IAA levels. The cost of publishing this paper was defrayed in part by the payment of page charges. Under postal regulations, this paper therefore must be hereby marked advertisement solely to indicate this fact.

'Soil Scientist.

${ }^{2}$ Research Horticulturist. acter to the scion (Suzuki et al., 1988) but they do alter above-ground dry-matter partitioning. DeJong and Doyle (1984) demonstrated that minimally pruned dwarf trees had more dry-matter partitioning to leaves, fine branches, and fruit and less to wood, with lower leaf N compared to "open-vase" standard size trees. In contrast, Scorza et al. (1986) found that 3-year-old unpruned dwarf trees partitioned a higher percentage of dry weight to 1- and 2-year-old wood than did standard trees, and fruit dry-matter partitioning did not differ with tree type. Peach (Natali et al., 1985; Natali et al., 1983; Young and Houser, 1980) and apple (Olien and Lakso, 1984) rootstocks also affect plant water relations. In citrus, the hydraulic conductivity of the root system is altered by the rootstock (Ramos and Kaufman, 1979; Syvertsen, 1981).

In this study, we tested reciprocal grafts of standard and dwarf phenotypes and measured their effect on cytokinin, IAA, and GA levels in root xylem exudate, dry-matter partitioning, and root resistance to water flow to further characterize rootstock-scion interactions in peach.
One-year-old seedling rootstocks of 'Elberta' (tall) and 'Juseito' (dwarf) were grafted $10 \mathrm{~cm}$ above the soil line with buds of 'Loring' (tall), 'Elberta', 'Empress' (dwarf), and 'Juseito'. Trees were grown in 7-liter containers with a peat medium and were fertilized weekly and watered twice daily. Trees were grafted in Spring 1987 and grown in a greenhouse until August, when they were destructively sampled. At the time of sampling, trees were well watered and the tops cut off $5 \mathrm{~cm}$ above the graft union. The study had five single-tree replications. Leaf and stem wood weight were measured on an ovendry (80C) basis. The root system and $15-\mathrm{cm}$ trunk were placed into a modified Scholander pressure chamber with the trunk extending 5 to $10 \mathrm{~cm}$ from the chamber. Bark and phloem were removed from the area and a tube was attached. A pressure of $0.2 \mathrm{MPa}$ was applied to the root system for a total of $90 \mathrm{~min}$, and the volume of exudate was measured by collection in a plastic tube at 30 and $90 \mathrm{~min}$. The initial $30 \mathrm{~min}$ of exudation was considered equilibration time, and only the volume from 30 to 90 min was used in the calculations of resistance to water flow. The volume of exudate per $30 \mathrm{~min}$ did not vary significantly between treatments during this period. Xylem exudate was frozen upon completion of the resistance measurement. Four soil cores $\left(98 \mathrm{~cm}^{3}\right.$ each) of the root mass were washed and root length density (cm root $/ \mathrm{cm}^{3}$ soil) measured using the line intersect method (Tennant, 1975). Total root length per tree was estimated from the four soil cores. Resistance to water flow was calculated as:

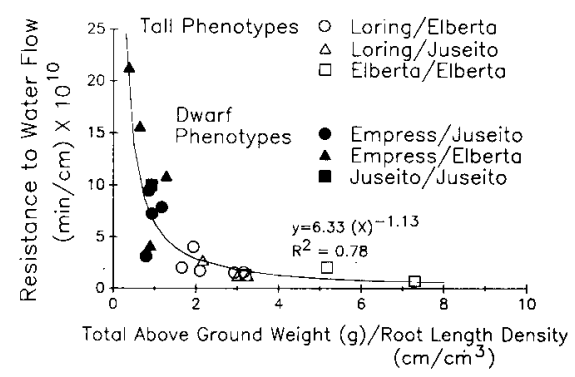

Fig. 1. Relationship between (total top weight/ root length density) and root system hydraulic resistance. 
Table 1. Effect of scion-rootstock combinations on growth characteristics and root resistance.

\begin{tabular}{|c|c|c|c|c|c|c|c|c|c|c|}
\hline \multirow[b]{2}{*}{ Scion } & \multirow[b]{2}{*}{ Rootstock } & \multirow[b]{2}{*}{$\begin{array}{l}\text { Scion } \\
\text { phenotype }\end{array}$} & \multirow[b]{2}{*}{$\begin{array}{c}\mathrm{RLD}^{2} \\
\left(\mathrm{~cm} \cdot \mathrm{cm}^{-3}\right)\end{array}$} & \multicolumn{5}{|c|}{ Weight (g) } & \multirow{2}{*}{$\begin{array}{c}\text { Resistance (R) } \\
\text { to water } \\
\text { flow (min. } \\
\mathrm{cm}^{-1} \times 10^{10}\end{array}$} & \multirow[b]{2}{*}{$\begin{array}{l}\text { Replications } \\
\text { for (R) } \\
\text { measurements }\end{array}$} \\
\hline & & & & Leaf & Stem & $\begin{array}{l}\text { Total } \\
\text { above- } \\
\text { ground }\end{array}$ & Lcaf/stcm & $\begin{array}{c}\text { Total } \\
\text { above- } \\
\text { ground/RLD² }\end{array}$ & & \\
\hline \multirow[t]{2}{*}{ Loring } & Elberta & Tall & $54.0 \mathrm{a}^{\mathrm{y}}$ & 57.8 a & $67.8 \mathrm{ab}$ & $125.6 \mathrm{a}$ & $0.88 \mathrm{~b}$ & $2.35 \mathrm{bc}$ & $2.23 \mathrm{c}$ & 5 \\
\hline & Juseito & Tall & $40.0 \mathrm{~b}$ & $51.0 \mathrm{a}$ & $59.7 \mathrm{~b}$ & $110.7 \mathrm{a}$ & $0.87 \mathrm{~b}$ & $2.81 \mathrm{~b}$ & $1.78 \mathrm{c}$ & 3 \\
\hline Elberta & Elberta & Tall & $29.6 \mathrm{c}$ & $51.0 \mathrm{a}$ & $82.3 \mathrm{a}$ & $133.3 \mathrm{a}$ & $0.63 \mathrm{~b}$ & $4.72 \mathrm{a}$ & $1.40 \mathrm{c}$ & 3 \\
\hline Juseito & Juseito & Dwarf & $7.2 \mathrm{~d}$ & $6.7 \mathrm{~b}$ & $7.3 \mathrm{c}$ & $14.0 \mathrm{~b}$ & $0.78 \mathrm{~b}$ & $2.06 \mathrm{bc}$ & $10.02^{x}$ & 1 \\
\hline \multirow[t]{2}{*}{ Empress } & Juseito & Dwarf & $31.2 \mathrm{bc}$ & $18.6 \mathrm{~b}$ & $9.4 \mathrm{c}$ & $28.0 \mathrm{~b}$ & $2.02 \mathrm{a}$ & $0.91 \mathrm{c}$ & $6.95 \mathrm{~b}$ & 4 \\
\hline & Elberta & Dwarf & $28.2 \mathrm{c}$ & $10.8 \mathrm{~b}$ & $9.0 \mathrm{c}$ & $19.8 \mathrm{~b}$ & $1.18 \mathrm{~b}$ & $0.80 \mathrm{c}$ & $15.96 \mathrm{a}$ & 4 \\
\hline \multicolumn{11}{|c|}{ Linear contrasts } \\
\hline \multirow{2}{*}{\multicolumn{3}{|c|}{$\begin{array}{l}\text { Tall vs. dwarf phenotype } \\
\text { Elberta vs. Juseito rootstock }\end{array}$}} & $*$ & $*$ & $*$ & $*$ & NS & NS & $*$ & \\
\hline & & & NS & NS & NS & NS & NS & NS & NS & NS \\
\hline
\end{tabular}

${ }^{2} \mathrm{RLD}$, root length density.

yMean separation within columns by Duncan's multiple range test, $P=0.05(\mathrm{n}=5)$.

*Treatment not included in analysis of variance.

NS.*Nonsignificant or significant difference at $P=0.05(\mathrm{n}=5)$.

Table 2. Rootstock and phenotype effects on phytohormone content of xylem exudate. ${ }^{2}$

\begin{tabular}{llccc}
\hline \hline Rootstock & Scion & $\mathrm{N}$ & $\begin{array}{c}\text { t-ZR-like } \\
\left(10^{-9} \mathrm{Molar}\right)\end{array}$ & $\begin{array}{c}\text { IAA } \\
\left(10^{-8} \text { Molar }\right)\end{array}$ \\
\hline Elberta & phenotype & 10 & $2.6 \mathrm{~b}^{\mathbf{y}}$ & $4.7 \mathrm{~b}^{\mathbf{x}}$ \\
& Tall & 5 & $30 \mathrm{a}$ & $7.6 \mathrm{~b}$ \\
\multirow{2}{*}{ Juseito } & Dwarf & 5 & $5.3 \mathrm{~b}$ & $5.0 \mathrm{~b}$ \\
& Tall & 10 & $36 \mathrm{a}$ & $25.8 \mathrm{a}$ \\
\hline
\end{tabular}

${ }^{26} \times 10^{-8} \mathrm{M} \mathrm{GA}_{3}$ was the lowest level of sensitivity in the bioassay; no values were higher.

${ }^{y}$ Values followed by the same letter within a column are not significantly different based on linear contrasts $(P=0.05)$.

xValues followed by the same letter within a column are not significantly different based on mean separation by the Ryan-Einot-Gabriel-Welsch test $(P=0.10)$.

$$
\left.\mathbf{R}=(\mathrm{A} \Psi)\left(\mathbf{R}_{v}\right) / \mathbf{Q A}\right)
$$

where $\mathrm{R}=$ root resistance to water flow $\left(\min \cdot \mathrm{cm}^{-1}\right) ; \mathrm{A} \Psi=$ pressure head $\left(\mathrm{cm} \mathrm{H}_{2} \mathrm{O}\right)$; $\mathrm{Q}=$ exudation rate per unit cross sectional area $\left(\mathrm{cm}^{3} \cdot \mathrm{c} \mathrm{m}^{-2} \cdot \mathrm{min}^{-1}\right) ; \mathrm{Rv}=$ total root length $(\mathrm{cm}) ; \mathrm{A}=$ area of xylem $\left(\mathrm{cm}^{2}\right)$.

The root hydraulic resistance measurements assume an undisturbed root system. In the case of Juseito/Juseito, only a single tree could be measured with confidence that the roots had not been broken as the tree was fitted into the pressure chamber. For all other rootstocks-scion combinations, at least three of the five replications were measured with confidence that no roots were broken during installation. In cases where root breakage was suspected, exudate was collected and all growth variables measured, but hydraulic resistance was not calculated. We are assuming that the phytohormone content of xylem sap expressed at a $0.2 \mathrm{MPa}$ potential reflects the concentration of phytohormones carried in the transpiration stream.

Trans-zeatin riboside ( $\mathrm{t}-\mathrm{ZR}$ ) was measured in undiluted xylem exudate using prepared immunoassay test kits (Phytodetek, San Bruno, Calif.). Due to cross reactivity with other cytokinins, the data are referred to as t-ZR-like activity levels. Serial dilution of four samples representing the range of phenotypes indicated there was no statistical evidence of nonspecific binding in the xylem exudate.

Gibberellin-like activity was determined using a dwarf-rice bioassay (Murakami, 1968). Seeds of 'Tan-ginbozu' (Oryza sativa L.) were germinated at $27 \mathrm{C}$ for 3 days. Ten seeds were placed in a paper cup containing
$0.4 \%$ agar and grown for 3 days at $27 \mathrm{C}$ in a growth chamber with relative humidity approaching $100 \%$ and fluorescent lights of intensity $\approx 100 \mu \mathrm{mol} \cdot \mathrm{m}^{-2} \cdot \mathrm{s}^{-1}$. Gibberelic acid standards were prepared from GA, in $95 \%$ ethanol. The standard curve included untreated plants, $95 \%$ ethanol, water, and GA, $(0.2,2,20$, and $200 \mathrm{ng} / \mu \mathrm{l})$. A 0.5 - $\mu$ l aliquot of sample or standard was placed between the coleoptile and first leaf using a $10 \mu \mathrm{l}$ syringe. Plants were grown an additional 3 days and the length of the second leaf measured as the bioassay response variable. Preliminary tests indicated that the dwarf rice response was insensitive to ABA, N-6benzyladenine and IAA $\left(2 \times 10^{-4} \mathrm{M}\right)$. A serial dilution of four samples spiked with $100 \mathrm{ng}$ GA, representing the four rootstock : scion phenotypes, indicated no statistical evidence of inhibitors of the bioassay were present in the xylem exudate.

Indole-3-acetic acid (IAA) was measured in xylem exudate using gas chromatography with a mass spectrometer detector (GC-MS) (Hewlett Packard 5871 A). Samples for IAA analysis were spiked with $10.5 \mathrm{ng}{ }^{13} \mathrm{C}_{\mathrm{s}} \mathrm{IAA}$ (Cohen et al. 1986) before high performance liquid chromatography (HPLC) purification. Xylem sap samples were eluted through a 10-cm Spherisorb ODS-1 (Thomson Instrument Co., Springfield, Va.). HPLC column with $30 \%$ methanol/water containing $1 \%$ acetic acid. The flow rate was $1 \mathrm{ml} \cdot \mathrm{min}^{-1}$. Peak identification of IAA used a fluorescence spectrophotometer (EX $285 \mathrm{~nm}$ and EM $360 \mathrm{~nm}$ ) (Sandberg et al., 1981). The HPLC fraction was methylated (Cohen, 1984) and analyzed using selected ion monitoring at $\mathrm{m} / \mathrm{Z} 130,136,189$, and 195. Quantifi- cation of endogenous IAA levels by isotope dilution analysis was based on the relative abundance of ${ }^{12} \mathrm{C}(\mathrm{m} / \mathrm{Z} 189$ and 130$)$ and ${ }^{13} \mathrm{C}$ $(\mathrm{m} / \mathrm{Z} 195$ and 136) IAA ions, as described by Cohen et al. (1986).

All data. were analyzed as a completely randomized design with five replications, except for hydraulic resistance, which had a variable number of replications (Table 1). Linear contrasts were constructed to test rootstock ('Elberta' vs. 'Juseito') and phenotype (tall vs. dwarf) for growth and phytohormone level. Mean separation of rootstock-scion combinations by Duncan's multiple range test and Ryan-Einot-Gabriel-Welsch are presented at $P=0.05$ and 0.10 , respectively. Regression analysis and linear contracts used a significance level of $P=0.05$.

'Juseito' and 'Empress' are dwarf and 'Loring' and 'Elberta' have a tall stature when self-rooted or when used as the scion. The expression of a dwarf or tall phenotype resulted in differences in root length density (RLD), leaf, stem, and total above-ground dry weights (Table 1). Leaf, stem, total aboveground dry weights, and RLD were unaffected by rootstock. Scion characteristics determined the phenotype of the tree, tall or dwarf, irrespective of the rootstock.

The leaf weight : stem weight ratio or total weight : RLD ratio was not significantly related to the tall or dwarf phenotype, indicating overall dry-matter partitioning in these young trees was not altered by the rootstockscion combination. However, dwarf trees did tend to have a lower total weight : RLD ratio and a higher leaf weight : stem weight ratio than tall phenotypes. DeJong and Doyle (1984) reported that 6-year-old dwarf peach allocated a large percentage of above-ground dry weight to leaves and fine branches and a smaller percentage to the larger wood component, compared to standard size trees.

Root resistance to water flow (R) was lower in the tall rootstock-scion combinations (Table 1). While there was not a significant phenotype effect on the total weight : RLD ratio, there was a significant curvilinear relationship between the total weight : RLD and hydraulic resistance (Fig. 1). Rootstock-scion combinations with high total weight : RLD ratios (generally tall phenotypes) had lower 
hydraulic resistance than combinations with low total weight : RLD ratios (generally dwarf phenotypes). We did not make anatomical observations of the roots but observed that the dwarf phenotypes had a finer root system than the tall phenotypes. The total weight : RLD ratio relationship with $\mathrm{R}$ ignores root diameter, and it is possible that root diameter and the number of xylem vessels were reduced by the dwarfing scions.

t-ZR-like activity and IAA levels in the xylem sap were higher in the dwarfing scion combinations (Table 2). Elevated cytokinin levels have been associated with dwarfing in peach and apple. Nii and Kuroiwa (1986) found that exogenous sprays of 6-benzylamino purine reduced main leader growth in peach and promoted lateral branching, resulting in a more compact growth habit. Looney and Lane (1984) showed that shoot tips of dwarfing and spurry mutants of 'McIntosh' have high endogeneous cytokinin levels and lowered gibberellin-like activity. Similar to Looney and Lane (1984), we found elevated levels of t-ZR-Iike activity associated with dwarf growth habit, irrespective of the rootstock. We found no difference in $\mathrm{GA}_{3}$-like activity between phenotype or rootstock (Table 2), but activity was measured midseason when gibberellin activity is generally low in peach xylem (Christoferi and Filiti, 1981; Grochowska et al., 1984). Levels of IAA were also highest in the dwarf scion on Juseito rootstock and tended to be high for the dwarf scions on 'Elberta' rootstock. Grochowska et al. (1984) found similar results with low-vigor apple phenotypes. Since the root system is a major site of cytokinin synthesis (Incoll and Jewer, 1987), it is possible that the scion can influence cytokinin synthesis in the root system in addition to root hydraulic resistance and root and shoot growth. The elevated levels of t-ZR-like activity and IAA in xylem ex- udate of dwarf phenotypes suggest an insensitivity of growth to these phytohormones in respect to growth response or an inhibition by elevated levels. The elevated cytokinin and IAA activity in dwarf phenotypes demonstrates that the scion influenced cytokinin and IAA concentration in the xylem.

\section{Literature Cited}

Christoferi, G. and N. Filiti. 1981. Endogeneous growth regulator levels in normal and dwarf peach cultivars. Rivista Ortoflorofrutt. Ital. 65:329-342.

Cohen, J.D., B.G. Baldi, and J.P. Slovin. 1986. ${ }^{13} \mathrm{C}_{6}$-[Benzene ring]-indole-3-acetic acid: A new internal standard for quantitative mass spectral analysis of indole-3-acetic acid in plants. Plant Physiol. 80:14-19.

Cohen, J.D. 1984. Convenient apparatus for the generation of small amounts of diazomethane. J. Chromatography 303:193-196.

DeJong, T.M. and J.F. Doyle. 1984. Cropping efficiency, dry matter and nitrogen distribution immature genetic dwarf and standard peach trees. Acta Hort. 146:89-95.

Faust, M. 1989. Factors determining size of fruit trees. Physiology of temperate zone fruit trees. Wiley. New York. p. 235-274.

Grochowska, M.J., G.J. Buta, G.L. Steffens, and M. Faust. 1984. Endogenous auxin and gibberellin levels in low and high vigor apple seedlings. Acta Hort. 146:125-134.

Incoll, L.D. and P.C. Jewer. 1987. Cytokinins and the water relations of whole plants. Brit. Plant Growth Regulat. Group, Monogr. 14. p 85-97.

Looney, N.W. and W.D. Lane. 1984. Spur type growth mutants of 'McIntosh' apple: A review of their genetics, physiology and field performance. Acta Hort. 146:31-46.

Murakami, Y. 1968. A new rice seedling test for gibberellin, 'microdrop method' and its use for testing extracts of rice and morning glory. Bot. Mag. Tokyo. 81:33-43.

Natali, S., C. Xiloyannis and A. Barbieri. 1985. Water consumption of peach trees grafted on four different rootstocks. Acta Hort. 173:355362 .
Natali, S., C. Xiloyannis, J. Littardi, and A. Barbieri. 1983. Growth, yield and seasonal and diurnal water relations of peach trees grafted on different rootstocks. Rivista Ortoflorofrutt. Ital. 67:329-341.

Nii, N. and T. Kuroiwa. 1986. Morphological and anatomical development of peach shoot and leaves as influenced by 6-benzylamino purine. Acta Hort. 179:267-268.

Olien, W.C. and A.N. Lakso. 1984. A comparison of the dwarfing character and water relations of five apple rootstocks. Acta Hort. 146:151-158.

Ramos, C. and M.R. Kaufman. 1979. Hydraulic resistance of rough lemon roots. Physiol. Plant. 45:311-314.

Rom, R.C. 1988. Progress in peach rootstocks, p. 302-307. In: N.F. Childers and W.B. Sherman (eds.). The peach. Hort. Publ., Gainesville, Fla.

Sandberg, G., B. Anderson, and A. Dunberg. 1981. Identification of 3-indoleacetic acid in Pinus sylvestris $\mathrm{L}$. by gas chromatography-mass spectrometry, and quantitative analysis by ion-pair reversed-phased liquid chromatography with spectrofluorimetric detection. J. Chromatography 205:125-137.

Scorza, R., L; Zailong, G.W. Lightner, and L.E. Gilreath. 1986. Dry matter distribution and responses to pruning within a population of standard, semidwarf, compact, and dwarf peach seedlings. J. Amer. Soc. Hort. Sci. 111:541545.

Suzuki, K., S. Murase, and T. Yamazaki. 1988. Preliminary research for dwarfing rootstock of peach, p. 310. In: N.F. Childers and W.B. Sherman (eds.). The peach. Hort. Publ., Gainesville, Fla.

Syvertsen, J.P. 1981. Hydraulic conductivity of four commercial citrus rootstocks. J. Amer. Soc. Hort. Sci. 106:378-381.

Tennant, D. 1975. A test of a modified line intersect method of estimating root length. J. Ecol. 63:995-1001.

Young, E. and J. Houser. 1980. Influence. of Siberian $\mathrm{C}$ rootstock on peach bloom delay, water potential and pollen necrosis. J. Amer. Soc. Hort. Sci. 105:242-245. 